\title{
Blockchain Matters—Lex Cryptographia and the Displacement of Legal Symbolics and Imaginaries
}

\author{
Katrin Becker ${ }^{1}$
}

Accepted: 22 December 2021 / Published online: 6 January 2022

(C) The Author(s), under exclusive licence to Springer Nature B.V. 2022

\begin{abstract}
This article focusses on the social and legal implications that blockchain technology brings about, not only due to its ideological framework, but also, and especially, due to the concept of law it inaugurates. Thus, this article claims, that, by interlocking technological and legal structures, blockchain technology initiates a profound displacement of legal symbolics and imaginaries. It shows how blockchain law, by emancipating itself from three essential dimensions of law-language, territory, and the body-implies a profound disruption of how we perceive law and its legitimacy. Starting with an overview of the technological details of blockchain, the paper then addresses its ideological context and traces the underlying ideas, values and functions and their relation with-and impact on-the general perception of law and legal issues. By critically assessing the claim that blockchain will liberate the subject from any heteronymic constraints, this paper analyses to what extent this technology has social and legal implications that reach far beyond its virtual, purely blockchain-related scope of applications - and why this technology should matter to us all.
\end{abstract}

Keyword Blockchain · Interpretation · Legal symbolics · Social imaginary · Language $\cdot$ Body $\cdot$ Lex cryptographica

\section{Introduction}

Blockchain technology has been described as having the potential to disrupt every inch of society. By means of decentralization and disintermediation it is said to liberate the individual citizen from potentially corrupt institutions and data-greedy companies, to accelerate and facilitate administrative and legal processes. Blockchain is meant to function as a 'new and relatively perfected system for value objectification'

\section{Katrin Becker}

katrin.becker@uni.lu

1 Département Sciences Humaines, University of Luxembourg, 2, Avenue de l'Université, L-4365 Esch-sur-Alzette, Luxembourg 
(de Charentenay 2017) and thus to replace those third parties on which value systems such as currencies (bank), religions (church) or legal systems (state) have so far relied when objectifying, or determining, their values. As a result, a growing number of economic, legal and political associations are currently experimenting with blockchain applications. However, the enthusiasm with which this technology is welcomed tends to obscure the fact that it comes with a whole new set of sociotechnological imaginaries that are likely to have a profound impact on the juridicalcultural settings of society.

A prior Law \& Critique supplement in 2018 already gave a thorough overview over the ideological parameters, hidden politics and legal and regulatory challenges posed by the advent of blockchain technology. Aiming to 'cut through the problematic of blockchain hype', the supplement under the lead of Robert Herian shed a light on blockchain's nature as 'a type of control technology that displaces or even replaces law' (2018, p. 131), as a driving force for a new emerging legal field (Goldenfein and Leiter 2018) and on 'the future of sovereignty in a blockchain world' (Manski and Manski 2018, p. 151). This emerging legal field has since further developed, with the growing sector of 'legal tech', including applications sprouting up like decentralized dispute resolution, decentralized law firms etc.

In therefore only partial agreement with Herian's assessment that 'blockchain produces greater effects as an idea than an applied technology' (2018, p. 166), the present supplement will turn the focus to the broader social and legal implications that blockchain technology brings about, not only due to its ideological framework, but also, and especially, due to the concept of law it inaugurates. Thus, this article claims, that, due to its interlocking of technological and legal structures, blockchain technology initiates a profound displacement of the symbolic and imaginary basis of law. It will be shown how blockchain law, by emancipating itself from three essential dimensions of law-language, territory, and the body-implies a profound disruption of how we perceive law and its legitimacy. Starting with an overview of the technological details of blockchain, the paper will turn to its ideological context in order to trace the underlying ideas, values and functions and their relation with - and impact on-the general perception of law and legal issues. By critically assessing the claim that blockchain will liberate the subject from any heteronymic constraints, this paper will show to what extent this technology has social and legal implications that reach far beyond its virtual, purely blockchain-related scope of applicationsand why this technology should matter to us all.

\section{What is Blockchain?}

Let me start by giving a brief outline of the technological background. A blockchain is essentially a public, decentralized, digitized registry stored on peer-to-peer networked computers that enables the fully transparent storage and continuous updating of information, and their unchangeable concatenation in chains of transactions laid down in blocks. This technology was invented by Satoshi Nakamoto, a person or group of persons who founded the crypto-currency Bitcoin and have concealed their identities behind this pseudonym until today. Their idea was to render the need for 
trusted third parties superfluous by creating a collectively guaranteed and consensus-based, thus forgery-proof procedure for information storage. In order to illustrate the mechanism of a blockchain system, de Filippi and Wright describe it as a "tamper-resistant "book" with identical copies stored on a number of computers across the globe' (2018, p. 22). Whenever new content is added, all copies of the book are updated. However, while in a book we're dealing with pages, we are here finding 'blocks', i.e. 'unchangeable indications of correctness' (Hummler 2016), that comprise a heading consisting of a unique string of characters, or hash, representing all transactions contained in that block, a time stamp and a hash of the previous block. These blocks are then bound into the "'gapless" history' (Hummler 2016) of a continuous chain: the block-chain.

Due to a consensus-based procedure for storage (proof of work/proof of stake), which confirms the validity of any new information in a way that is accessible and verifiable for all parties involved, and due to the concatenation of the data and the decentralised nature of the system, a change or falsification of the stored information becomes im- or hardly possible, as this would require the consent of a majority of $51 \%$ of the parties involved in block creation, which is hardly achievable in most blockchains, especially in the case of dishonest intentions. Thus, and this is the central element of this technology, the trust in a third party guaranteeing the correctness of the information becomes superfluous-the talk is of trustless trust,i.e. trust in the underlying code of the blockchain is sufficient.

In addition to the Bitcoin blockchain, numerous other blockchains have to this day emerged, such as for example Ethereum, which go beyond the technological capacities of Bitcoin in that, in addition to monetary transactions, they offer the possibility 'to store or reference other forms of information, including what are essentially small computer programs' (de Filippi and Wright 2018, p. 27). This means that, due to the fact that each blockchain code contains an integrated crypto-currency, sending an amount of that specific crypto-currency or feeding the system with new information can trigger, automatically and in real time, a code change in another account or the actuation of a programmable machine. For example, when an agreed crypto-currency amount is received on the account of the owner or seller, the intelligent door of the rented apartment opens or the ownership of the digitizable object is transferred to the buyer. By means of these smart contracts, it is possible to transfer certain legal transactions into code and to integrate individually negotiated contractual conditions into the underlying algorithmic network of a blockchain in order to have them automatically executed. The possibility of forgery-proof storage of information and the unambiguous cryptological linking of transaction data to a specific person makes the execution of such contract-like programs especially secure.

These quasi-contractual programmes and structures, which can be executed transnationally and autonomously, i.e. 'independently of any government or other centralized authority' (de Filippi and Wright 2018, p. 207) are one of the main reasons why blockchain technology is said to have the ability to 'fracture economic and social processes, to bring intermediaries to their knees and to even attack the essence of institutions at their core' (Hummler 2016).

Next to those 'open blockchains', a growing number of two other kinds of blockchains are currently gaining popularity, which are however, in essence, thwarting the 
initial decentralizing purpose of the technology: while open blockchains offer free access and use to everyone, these so called private or hybrid blockchains (de Filippi and Wright 2018, p. 31; Plisson 2017, p. 20) increasingly implemented in the financial or state sectors, ${ }^{1}$ are managed by a central authority or consortium that controls access rights and the selection of members. These blockchains take recourse to central elements of open blockchains such as quasi-legal instruments and partly automated governance structures. Given their control mechanisms, however, they give rise to different concerns, especially those of the legitimacy and scope of power of those central organs. The administrative structures of these blockchains are often easier to control and to govern by traditional legal means, and they are starting to be implemented by nation state governments themselves. Depending on the conditions of their implementation, they therefore don't necessarily have the same impact that open blockchains do whose declared aim is to overcome the need for certain-if not all-traditional (legal) institutions. The following analysis will focus on the original-decentralized and open—blockchains.

\section{Blockchain Ideology: Cybernetics, Governance by Numbers, and Beyond}

In order to fully assess the social and legal implementations of this technology we shall start by taking a look at its ideological framework since, as Pierre Musso (2021) points out, every technology involves both a functional and a fictional dimension. As such it is an integral part of the symbolic and imaginary framework of a society - the very framework that constitutes the legitimating basis for law.

Each innovation comes with a set of 'images, metaphors, signs' and is thus 'the reflection of a whole vision of the world' (Baudrillard 1968, p. 39). It is therefore, at the same time, able to influence this imaginary and symbolic framework, by shaping social habits and the common perception of world, society and self. Taking a look at the blockchain's 'fictional' framework, its aims and ideas, ideals seem, at first sight, to be closely related to those of digitization in general: in essence, the idea of the blockchain community to create law, institutions and subject positions through programming and coding of algorithms is, just like digitization in general, based on an ideology which Alain Supiot (2015) has coined as 'Governance by numbers': this ideology was born at the crossroads between 'communism and [...] ultraliberalism': that is, on the one hand, the dream of a 'society without heteronomy', (2015, p. 408) which considers 'the law and the State as ruses of power and infringements on the sovereignty of individuals' (2015, p. 175), and, on the other hand, the belief in the power of numbers, in

\footnotetext{
1 cf. Dubai's administration (https://smartdubai.ae/initiatives/blockchain), Woolf University, (https:// woolf.university); supply chain projects (http://www.ipsoa.it/documents/impresa/contratti-dimpresa/ quotidiano/2019/01/07/blockchain-strategy-for-the-protection-of-made-italy-products); stock exchange (https://www.forbes.com/sites/ericervin/2018/08/16/blockchain-technology-set-to-revolutionize-globalstock-trading/).
} 
calculation as basis of society, of law and subjectivity and the belief in the possibility of programming them (2015, p. 244). According to Rouvroy and Stiegler this new way of perceiving ourselves and the world, of steering our society goes so far that, based on the exploitation of big data, we're dealing currently with a 'numbering of life itself, to which is substituted not a truth, but a numerical reality, a reality that claims to be the world, that is to say, that claims to be nonconstructed' (2015, p. 118).

As soon as it is "enough" to run algorithms on massive quantities of data to magically bring up hypotheses about the world, which will not necessarily be verified, but will be operational, one effectively has the impression of having found the Grail, of having attained the idea of a truth that no longer has to pass through any test, any investigation, any examination, in order to impose itself, and which, in order to emerge, no longer depends on any event (Rouvroy and Stiegler 2015, p. 118).

However, the ideas and ideals blockchain promotes basically start where the 'governance by numbers'-ideology has left off: namely at an 'exhaustion' of 'public trust in institutions' (Vigna and Casey 2018, p. 23) - a phenomenon that can easily be seen as a direct effect of this number- and algorithm-mediated functioning of society, in which, thanks to the growing importance of calculation and algorithms, citizens have allegedly been freed 'from any social construction, from any representation, in favour of an immediate access, of an osmosis with the world itself in its invincible heterogeneity' (Rouvroy and Stiegler 2015, p. 117).

Blockchain technology now claims to overcome the need for those-no longer-trusted thirds, that is all institutions and persons who traditionally serve as mediators of those 'social constructions' and 'representations'. What is faded out in this claim, however, is the fact that this implies at the same time the idea of overcoming the need to trust in the basis of that which those 'third parties' usually represent, that authorizes them to serve as legitimating entity, to being trusted-that structure of faith that we're encountering in all societies, as Alain Supiot points out, when he explains that:

any government requires that its members give it credit, both in the strongest and most technical sense of the word 'credit', in order to be sustainable. The strongest, because it is indeed a matter of belief, in the dogmatic sense: faith in a legal Truth that is imposed on us. The most technical, because this belief is not a private affair, but a claim opposable to all and guaranteed by a Third Party (Supiot 2015, p. 300).

In other words: for all 'thirds', for all mediating institutions in society that guarantee the common values underlying all social interactions and transactions to be able to act as legitimate, they too need to be legitimized. A valid bond of faith needs to be established between them and their addressees. The individual subject will only recognise itself as subject and part of the institutional structure of society, will only recognise the latter as legitimate, if its own ideas, its own interpretations, its imaginary, interweave with those at the foundation of 
legitimacy, i.e. with the 'social imaginary' (Castoriadis), in which the collective 'symbolism is so deeply rooted' (Fressard 2005, p. 143). Every society thus creates a great Third, a symbolic referent, an imaginary framework, which serves as legitimating basis for the institutions.

With its claim to overcome the need for trusted thirds, to free the individual from any institutional constraints, however, blockchain technology is not only introducing new perceptions of the world and the self, and thus influencing the imaginary basis of our society. It is moreover set out to attack that very logic we described as lying at the heart of a society governed by law: by allegedly encoding a consensually and forge-proof vision of the world, a 'truth that's more reliable than any truth we've ever seen' (Vigna and Casey 2018, p. 20), the code itself becomes the symbolic referent and abolishes at the same time the need for the mentioned bond of faith. Thanks to its open access, everyone can now have access to the algorithmically established 'truth-realities' of a blockchain. The only trust needed now is in the allegedly consensually coded algorithm at the base of the blockchain. As a result, traditional institutions or human representatives who usually act as messengers of a society's underlying (truth-)vision of the world are being challenged, not only with regard to their trust potential but also regarding the need for their service: given that this code is at the same time the tool for programming a growing number of lifegoverning legal applications.

\section{Displacement of Symbolic and Imaginary Basis of Law}

In the next section we take a look at this law that blockchain creates, in order to show to what extent it initiates a displacement of the symbolic and imaginary basis of what we have so far referred to as law. The so called lex cryptographia is mainly constituted by the new quasi-legal structure of smart contracts that are being used for regulating and initiating two- or morefold relationships of (trustless) trust. Given that these smart contracts can be set up by two or more parties that are located anywhere across the globe, this law operates entirely detached from the traditional 'third party', i.e. the cultural and national basis of legal legitimacy. Lex cryptographia is a law that is no longer legitimized by a culturally established symbolic referent which it no longer needs to be as there is no longer a need for recognition or belief: by programming the code, the parties to a smart contract are making law, implying-or rather coding - the values they take to be fundamental, and initiating the law's automatic execution: legal basis, law writing, law and its enforcement fall into one.

The replacement of the symbolic referent with code, however, implies at the same time a profound displacement of the traditional imagery and symbolic basis of law: not only does the coded lex cryptographia initiate a detachment from the traditional symbolic referent as its legal legitimacy. It also dissociates the concept of law in general from those three dimensions of human life that are constitutive for the necessity to agree on a common representation of the world, and that are the core elements of the symbolic and imaginary framework a society's institutional and legal system are traditionally rooted in: the territory, language and the body. 
The following section will therefore focus on the legally relevant role of these three elements and on how the 'lex cryptographia' emancipates itself from them, in order to show that this new form of law proves to be in essence anti-representational. This section lays ground for the then following argument that by establishing this new concept of law, blockchain technology exceeds all existing innovations in digitization and algorithmization in its social and legal implications.

\section{Emancipation from Language and Interpretation}

Firstly, blockchain law initiates an emancipation from language. According to Supiot, 'the bonds of law and the bonds of speech converge, enabling every newborn child to become a member of humanity' (2007, p. viii). For 'before we can dispose of ourselves freely and say "I", we are already a subject of law, bound-sub-jectum: thrown under-by words which tie us to others' (Supiot 2007, p. viii). Every language represents a 'consensual representation of a world' (Supiot 2007, p. viii) in light of which the institutional system, the law and politics are constructed.

This logic is, as Garapon and Lassègue point out, no longer valid in the context of blockchain law, where language itself is being abolished as 'carrier of law' (2018, p. 146). Instead it is being replaced by the code of the blockchain. By 'linking a situation to a regime of truth through a technical act', i.e. by coding instead of naming 'what will henceforth be considered real by a public act', blockchain code proves to be 'a language without representation of the world' (Garapon and Lassègue 2018, p. 142); 'blockchain removes [the cut that opens the space of fiction (Ricoeur)], and the stage of representation is, to all intents and purposes, crushed' (Garapon and Lassègue 2018, p. 162). By converging word and thing in the blockchain algorithm, which is operating automatically once programmed, the room for interpretation is eliminated. In its 'if-then' structure, lex cryptographia operates according to the 'logical principle of noncontradiction' (Musso 2017, p. 56). It is conceived as free of 'anything ambivalent or paradoxical' (Musso 2017, p. 56), i.e. free of the irrational and unreasonable dimension that defines human and social life. Once it is programmed, it acts as 'robotic law'; all stages of a legal procedure, even sentences or penalties, are automated and executed independently from any controlling entity (cf. Garapon and Lassègue 2018, p. 146).

Thanks to distributed ledger, [these data] could be used to prevent [...] automated doors from opening for people whom a smart-contract risk-assessment service rates below a threshold of desirability. [...] Once delivered and booked into jails, smart courts could automate sentences based on an automated assessment of future crime potential (Bogost 2017).

\section{Emancipation from Territory}

Secondly, the decentralized blockchain structure cuts all legal ties with any territory. According to Pierre Legendre, a territory implies a 'genealogical connotation' with regard to the idea of society - as becomes obvious in 'the politico-legal term “patria” inherited from Latinity' (2009, p. 264). Traditionally, territory and text, as 
Peter Goodrich points out, overlap in a society's construction of the great Third: serving as the voice of the symbolic referent, the founding legal text is the expression of that social order established through the 'places, locations, social positions and legal expressions of subject and subjectivity' (2006, p. 33).

According to Supiot, the 'governance by numbers' has made first steps in deterritorializing law by replacing 'territorial inscription of laws' with a 'submission of [the] content [of laws] to a calculation of utility' (2008, p. 103). Thus, instead of being bound to a territory, the foundation of law is more and more often based on calculable 'economic harmonies that would preside over the functioning of human societies' (Supiot 2015, p. 103). So far, however, the symbolically charged numbers were still represented and mediated by territorially anchored institutions, legitimized by the nation state.

Blockchain law now claims to no longer need any tie to a traditional corpus or territory. The decentralized and algorithmic establishment of legitimacy implies the idea of a law that is completely detached from the 'corpus mysticum' of the state. Rule sets are therefore negotiated on a case-by-case basis, independently of any legal corpus, depending on the will of the respective transaction partners and the conditions of the individual situation.

The individual customization of applicable norms would capacitate individuals to determine the rules applicable to them in line with their respective preferences and to switch between rule sets depending on time and circumstance (Finck 2018, p. 80).

Even in the setting of possibly emerging community forms, the legal basis remains acephalous and virtual. According to Wright and de Filippi we are thus dealing with a 'new digital common law':

consisting of an interconnected system of rules interacting with one another in a reliable and predictable way, without the need of any third-party institution to enforce these rules (de Filippi and Wright 2015, p. 41).

Set up as 'decentralised borderless virtual nations' or 'cloud communities', these "“state-like" non-territorial polities' imply, so the argument goes, 'traditional characteristics of political communities' (Orgad 2018, p. 257):

People could band together and set rules for their own governance, collect taxes, and distribute wealth in ways the group believes is fair. Communities could form into nations, unbounded by geographical boundaries, and governed through a set of algorithmic rules that can be both established and enforced 
through voting mechanisms and smart contracts (de Filippi and Wright 2015, p. 39). ${ }^{2}$

By removing the territorial basis, however, these communities abolish, at the same time, the representational basis of democracy and of the law rooted therein: it is the contingency of our spatio-temporal presence that forces us to agree on a common worldview with those we happen to share our existence with. By creating opt-in legal systems, the need for compromise, for deliberation on what values the law should represent—and thus its democratic basis—is removed (De Filippi 2018, p. 275).

\section{Emancipation from the Body}

Thirdly, blockchain law conceives a form of legal subjectivity that abolishes its corporeality. According to Legendre and Supiot subjectivity is constituted by a process of division between the biological and symbolic, by which the body is, at the same time, inscribed into symbolic representation. In that sense, Legendre, referring to Lacan's mirror paradigm, explains that '[via] the path of representation it detaches itself from the state of a biological object and becomes fiction' (Legendre 1994, p. 41). By integrating the individual's body into the corpus of law, the legal institutions of a society guarantee that the body is not treated as a commodified object.

Again, with digitization, a first step has been taken into the direction of a matterfree existence ${ }^{3}$ : with e-residency that was inaugurated in Estonia in 2014 a form of virtual residency came into being which is supposed to be 'an international "passport" to the virtual world' (Sullivan and Burger 2017, p. 470). While this passport essentially represents an entry ticket to the Estonian economy, e-citizens remain generally bound by their 'national identity', and as such tied to the corpus of a nation as well as to the body ('biological citizenship') (Heinemann 2016, p. 8).

Blockchain-based subjectivity, however, is conceived as purely virtual and codeor else data-based, and thus independently of any institutional pre-definition. No longer 'dependent on a person's legal entitlement through citizenship or physical presence in a country' (Sullivan and Burger 2017, p. 472), the transnational, digitized subject gains what is called 'self-sovereign identity': it is enabled to 'manage [his/her] identity-related information [...] without the need to refer to any trusted authority or intermediary operator' (Wang and de Filippi 2020, p. 33), by facilitating

\footnotetext{
${ }^{2}$ An already existing example is the Bitnation project. With its 'Pangea platform' it enables anyone to create her own state or 'Decentralised Borderless Voluntary Nation (DBVN)': 'Through simply downloading an app on your smartphone, you can choose your code of law, your preferred arbitration method, write a smart contract, and get married, title your land, notarize a will, incorporate a company, get health insurance, and much more, in just a few minutes for a couple of dollars. It is backed by an ID and reputation system dispute resolution, and an app library where people can upload and share or sell their own do-it-yourself governance apps' (https://blog.bitnation.co/, 2015).

3 cf. la 'Declaration of the Independence of Cyberspace' https://www.eff.org/de/cyberspace-independen ce.
} 
'trust and the secure sharing of information with multiple independent parties across broad networks' (Ciobanu 2018).

With regard to its legal activities, the subject therefore obtains the power to define, individually and on a case-by-case basis, the rules of its globally operative, automated and peer-to-peer legitimized existence. It is bound by-or binds itself to- the code alone, i.e. lex cryptographia, the foundation of which, as we have seen, is itself acephalous and fluid: individually negotiable, this law's terms and provisions depend on the respective transactional context or on the membership of the chosen 'cloud community'. In that sense, the subject is conceived of as not only being detached from the heteronomous sovereignty of state and law-but eventually also from the heteronomy of its own body: this begins with the idea of 'decentralized government services' ('just because you live in a particular geography should not restrict you to certain government services' (Swan 2015, p. 47)) and ends with the plans for 'personal thinking blockchains', in the sense of 'mindfiles', i.e. 'the recording of every "transaction" in the sense of capturing every thought and emotion of every entity, human and machine, encoding and archiving this activity into life-logging blockchains' (Swan 2015, p. 43).

\section{Why Do Blockchain Technology and Lex Cryptographia Matter?}

Looking at the scenarios described above, the impacts of blockchain technology and its law seem, at first sight, to be limited to only a small number of legal contexts, and especially to the virtual realm. And as a matter of fact, the idea of a total emancipation of the body, of a complete disembodiment, the idea that blockchain would enable us to establish and administer social life in a completely virtual and body-less, text-less, and state-less manner, seems downright unrealistic and utopian (or rather dystopian). In a similar vein, authors such as Michèle Finck and others stress that the idea that blockchain technology could replace state and law is 'misguided', that the "success of blockchains is hence to no small degree contingent on recognition by the real world, and it simply cannot refuse to account for external legal requirements and systems' (Finck 2018, p. 85); that '[c]ompliance with existing legal systems is required if blockchain and blockchain-based applications are to have a real-world impact' (Finck 2018, p. 86).

However, not only in the economic field, but also in political and legal contexts, we are currently observing a growing recognition of certain blockchain applications, especially those that pursue, in an increasingly sophisticated way, the emancipation of traditional 'legal systems'. In the following, we shall therefore analyse why this new form of law has implications that go beyond its virtual and disembodied realm of applications and why it should be of concern to us all. Human life is necessarily bound to physical and bodily presence. And so it seems all the more appropriate to take a critical look at the imaginary and symbolic consequences that an expansion of the scope of application of these legal instruments, based on ideas of a virtual and disembodied existence, could entail; as well as to critically assess the claim that 
blockchain technology empowers the individual subject to be 'self-sovereign' by abolishing the heteronymic constraints of political and economic institutions.

\section{Lex Cryptographia's Impact on the Traditional Social and Legal Imaginary}

Firstly, we need to raise the question of what ideas of law, of legal values and ideals, initiated by this technology, might encroach on the traditional 'collective imagination'. In this context, it seems appropriate to turn our focus to those blockchain applications that are currently enjoying increasing success, and that not only strive to establish decentralized and contractualist institutional structures, detached from national corpora and nomos, but which aim at establishing a new conception of justice: the platforms for 'decentralized justice' or 'crowdsourced arbitration'.

In line with the general effort of blockchain technology proponents, these applications promise to overcome the need to resort to national jurisdictions even in the event of legal disputes. This means that where-despite all efforts-the non-programmable nature of a human person, or a non-erasable ambivalence of contractual provisions requires legal interpretation or a posteriori dispute resolution, specific dispute resolution tools that operate transnationally and trans-jurisdictionally shall now take effect. Unlike existing online dispute resolution (ODR) platforms that remain linked to existing institutions of jurisprudence, this approach relies on "crowdsourcing the adjudication of disputes to a worldwide pool of willing jurorarbitrators', 'all of whom interact through decentralised apps ("dApps") built on top of the blockchain' (Metzger 2019, p. 81; p. 83).

In order to give a brief overview of their functioning, we will take a look at the most developed, ambitious and successful project among those that exist so far ${ }^{4}$ : the application Kleros, which, by setting up 'decentralized courts', promises 'fast, open and affordable justice for all' (Ast et al. 2019), which is not only supposed to 'mak[e] things faster and less expensive, but [...] also [to] mak[e] the decisions better' (Winter 2019).

In accordance with the basic approach of blockchain technology, the referral to this decentralized jurisdiction occurs automatically, i.e. following the occurrence of certain conflicting circumstances in the context of an intelligent contract. It is therefore a procedure integrated into the contractual programming that does not cancel the automatic execution of the contract but suspends it until the conflict is resolved.

The modus operandi of the so-called arbitration court is then based on a combination of crypto-economic principles and game theory. It departs from the assumption that people unknown to each other, who do not communicate and do not trust each other, can still reach a consensus by choosing certain 'focal points' (called Schelling points) that, so they assume, have characteristics that will lead others to choose them as well. In the case of the Kleros application, these focal points are 'honesty and fairness', i.e. the consensus to be determined is the just-or rather 'true and

\footnotetext{
${ }^{4}$ Such as Aragon, Jur, OATH, Juris, etc.—cf. a detailed listing in Metzger 2019.
} 
fair' - judgment in a given dispute; the 'people unknown to each other' are jurors selected at random, according to a random number generator, on a case-by-case basis. Their function is to reach, independently of each other, a consensus of justice, which ultimately turns out to be a majority decision: the idea is 'to vote what they think, other parties think, other parties think [...] is honest and fair' (Ast et al. 2019). And 'the resolution with the most juror support wins' (Schmitz and Rule 2019, p. 118). The qualification as well as the incentive to participate in these proceedings is financial: in order to become a juror you have to pay a certain amount of 'Pinakion' tokens; once this is done, you are then encouraged to participate impartially, namely, 'to vote with the majority because [you] win tokens' (Fenton 2019).

So far, 'applications for Kleros include managing disputes over escrow accounts and insurance payments, and resolving claims of abuse on social networks' (Schmitz and Rule 2019, p. 188), but the goal is clearly to expand and intensify the scope of implementation (George 2018). Thus, the 'Kleros Fellowship of Justice' advances projects aimed at developing new use cases in the corporate sector, but also in international arbitration contexts and specific judicial systems (currently, among others: India, Colombia, Mexico). And even in the context of the current Covid-19 pandemic, the importance of this possibility of virtual 'decentralized arbitration' is increasingly celebrated as most promising solution (Aves 2020).

In addition to this platform's expansion of scope, and the recognition that accompanies it, ${ }^{5}$ and its corollary of an inevitable narrowing of the field of activity of traditional jurisdictions, it seems particularly relevant to consider these platforms with regard to the symbolic and imaginary basis of the here promoted law. Thus, the first question that arises is the following: could this transjurisdictional jury give rise to a new-representational—body based on new conceptions, values and ideals of law? ${ }^{6}$ In other words: does the suspension of the automatic execution of the contract open a loophole, in the sense of a new Ricoeurian 'cut', and does it therefore base the technology, contrary to what was described above as its anti-representational nature, on a new_-and even 'better' — set of law-founding ideas, imaginaries, values?

Indeed, this dispute resolution procedure that requires human intervention might, at first glance, be considered as a moment where new imaginary and symbolic grounds of law could arise. If this were the case, a more critical focus would then need to be turned to who the jurors are, as well as to how they reach their verdict. Here the occasional concerns about the selection and recruitment of jurors, which raise questions of integrity and balance, need to be highlighted (Metzger 2019, p. 100). Even more of an issue would then be the question whether game theory and the Schelling Points can in fact ensure that 'a group of unidentifiable, dispersed people who may have different legal and cultural understandings of a particular dispute will be able to coalesce around a "correct outcome", (Metzger 2019, p. 100).

\footnotetext{
5 The Public Investment Bank of France awarded the Kleros project with the highly endowed innovation grant: https://blog.kleros.io/french-bank-grants-subsidy-to-kleros/.

6 Thus, the founder of the Kleros suggests an analogy with the Greek legal system, which he further emphasizes by the denomination of the jury system (Kleros) and tokens like Pinakion (Ast 2017).
} 
And yet, it is not only the mention of those 'dispersed people who may have different legal and cultural understandings' (Metzger 2019, p. 100), i.e. the once again acephalous and fluctuating foundation of this concept of law, that leads us to conclude that this site remains faithful to the basic-anti-representational-principles of the blockchain. By considering its underlying conception of justice, defined by majority decisions and the correctness of data, we understand that the here promoted idea of justice has nothing to do with its traditional conception. Contrary to the conception of justice as being anchored in an ultimate negativity, as a founding axiom of the legal system and as a dogmatic foundation 'which itself cannot be founded' (Fabre-Magnan 2018, p. 308), the so-called decentralized justice is now defined as the victory of the 'correct' vote, of the vote of the majority. Justice thus becomes quantifiable, measurable, and, betting on the 'winners on the blockchain', it is transformed into 'mob justice' (Schmitz and Rule 2019, p. 117). And ultimately: any attempt to interpret the blockchain juror activity as a transcultural or transnational process of collective search for that indefinable sense of justice, which, as Simone Weil describes it, lies ineffably at the bottom of the heart of every human being (Weil 1962, p. 10), and which might therefore connect the dispersed jurors to each other, seems to be foredoomed by the websites insisting on the fact that the 'most obvious' reason for becoming a juror is the fact that 'you can make money'.

Returning to the question of which ideas, values, and imaginaries might encroach with the expansion of those applications on the 'collective imagination', we are learning that the dissemination of a new concept of justice is precisely the declared aim of the founders and followers of these decentralized courts. In this vein, Professor Eyal Winter complains about the still widespread, 'very difficult' and yet to be overcome attitude that 'you can't let a computer decide justice' (2019). And the founder of the Kleros app, Federico Ast, adds: 'I always say that Kleros is about building computer software, but it's also about upgrading the mental software of what people see as justice'(Ast in Winter 2019).

\section{The Subject of Lex Cryptographia: Self-Sovereignity_or New Heteronomies?}

Next to these symbolic and imaginary consequences that, by themselves, should already be reason enough to not let the expansion of blockchain technology proceed unnoticed, the blockchain claim to free the individual subject from all institutional and other (bodily) heteronymic constraints has, secondly, much more concrete and pressing implications. We should therefore consider to what degree the code is in fact an abolishment of institutional heteronomies, and assess especially critically the fact that the inevitably heteronomous effect of the code itself is generally not perceived as a restriction of autonomy. In this context, one is usually referred to the blockchain's consensual foundations. This argumentation, however, seems problematic for two reasons.

On the one hand, programming the code underlying a blockchain requires (at least until now) specific computer skills. Programming the basis of a blockchain network therefore lies in the hands of a few individual programmers. In addition, the 
admission of new data, values, etc., is essentially determined by miners, who thus occupy a central position in the orientation of a blockchain (Atzori 2017, p. 17). The political-legal dimension of their influence becomes especially visible in use cases like the discussed crowdsourced arbitration, where programmers not only decide about what is to be considered a legal dispute or how the jurors are being chosen, but are predefining the judgments from which the jurors can choose. This necessarily raises the question of the emergence of new power structures, as Atzori explains: 'In a world increasingly reliant on technology and ruled by networks, whoever owns and controls these platforms will always have a significant power over civil society on a global scale' (Atzori 2017, p. 29). In this context, it is notably worth referring back to the increasing implementation of private or hybrid blockchains, that operate under the control of a central management organ, which is thus inevitably bestowed with ever greater power.

On the other hand, the question of whether we are actually dealing with an abolishment of institutional constraints, is all the more relevant, if we turn back our focus to the question of the body. As mentioned above, Finck pointed out that it is 'misguided' to believe that blockchains could develop any 'real world'-impact as long as they are non-compliant with existing legal systems. Taking a closer look, however, at what certain blockchain applications promise, it does not seem any less misguided to believe that lex cryptographia remains limited to its virtual space of application, as long as it is not recognized by the 'real world'. More precisely, we need to realize that even in its virtual, disembodied dimension it certainly does have a relevance with regard to what here seems to be called the 'real world'.

Let me explain in detail: we are dealing with a robotized law, ultimately nothing more than a system of programming, which covers everything that can obey or comply with its rules-meaning, in this context, everything that is programmable. The first condition to becoming an integral part of this legal system is therefore to be programmable - a condition that, due to the 'progressive colonisation of the physical world by connected objects' (Rouvroy 2018, p. 418), is about to be met by an increasing number of actually material—physically present—objects: 'In 2025, [...] every "normally connected" person is likely to interact with connected devices or objects every eighteen seconds, i.e. 4800 times a day' (Rouvroy 2018, p. 418). ${ }^{7}$ As a result, lex cryptographia increasingly has the capacity to leave its virtual scope and extend into areas of material presence.

The individual subject itself-as legal subject of a lex cryptographia systemappears, as shown above, in the process of its 'blockchainification' (Bogost 2017) primarily as a data carrier: the data that the subject discloses for insurance purposes, property transfers, identity management, etc. will define its identity and will also be linked, through algorithmic programming, to provisions of property, etc. And thus, with regard to the blockchainified property of these data carriers-legal subjects, we

\footnotetext{
7 With reference to David Reinsel, John Gantz, John Rydning, Data Age 2025: The Evolution of Data to Life-Critical, April 2017, https://www.import.io/wp-content/uploads/2017/04/Seagate-WP-DataA ge2025-March-2017.pdf.
} 
are witnessing what could be called a superposing not only of the law, its juridical fundament and its execution, but also of the legal subject and object:

In the case of smart property [...], ownership could be both defined and managed by source code. A person who qualifies as the technological owner (as opposed to the legal owner) of smart property enjoys absolute sovereignty over that resource, which cannot be seized by anyone unless specifically provided for by the underlying code (de Filippi and Wright 2015, p. 35).

[Smart contracts] could be used to automatically check a decentralized online identity platform and digitized criminal records to assess whether the person satisfied certain preconditions that define who can and who cannot own or use guns. [...] More drastically, smart contracts could be tied to an Internet-connected gun, which could only be operated if these pre-conditions were met (de Filippi and Wright 2015, p. 36).

Contrary to what is usually proclaimed with regard to blockchain's relevance and implementation, the physical presence of the 'self-sovereign' subject is therefore very much affected. Due to its unprogrammable nature, the subject's body and physical presence, necessarily remains excluded from the legal system of blockchain but is yet no less concerned by its scope of application. The concept of subjectivity that emerges here fundamentally contradicts the traditional conception of legal subjectivity, in particular according to the perspective of Legendre, Supiot, and Musso: as explained above, these authors understand subjectivity as being constituted by separating the body from its biological dimension, by inscribing it into the symbolic representation, which in turn, through the concept of legal personality, guarantees that the body is not treated as a commodified object.

In the anti-representational logic of blockchain technology, we observe a contrary dynamic: as a non-programmable object, the body has no place and is non-existent in the universe of lex cryptographia. In blockchain structures, there is no symbolic representation, and thus - in the sense of a reverse application of Legendre's logic - the body loses its vested place. In the context of blockchain law, the legal personality in its traditional sense of 'unity of body and mind' (Supiot 2017, p. 10) dissolves. The body is left behind in a dimension of unrepresented presence and finds itself, vis-à-vis the blockchain law, inevitably degraded to a biological object. As a pure body [Leib] it is, in this very unrepresented presence, confronted with objects belonging to a different realm of presence, of a robotic and therefore non-symbolic legal order.

In other words, with the increase of smart objects, of material objects that can be integrated into the algorithmic system of a blockchain, a new form of programmed, automatic and ultimately robotized presence emerges - a presence that all those nonprogrammable presences are confronted with which necessarily remain excluded from the anti-representational law of blockchain.

Regardless of the protection of the body in the traditional rule of law, these kinds of confrontations between unrepresented presence and robotized presence should demand our attention-and make obvious why 'blockchain matters' already now. Whenever blockchain exercises its legal power, it comes with the risk of triggering clashes between two different kinds of presences, between two different legal systems. Ensuring blockchain's 'compliance with existing legal systems' (Finck 2018, p. 86) is 
therefore not enough: it proves to be a simple remedy for what turns out to be a fundamental division between two different types of organizing presence. And this division urgently needs to be addressed: each request to bridge blockchain legal systems 'with legal systems and their overarching ideals' (Finck 2018, p. 80) should take into account the role of the body, language and territory, i.e. those elements of human existence which are inextricably bound to interpretation, to symbolic and imaginary representation, and which therefore necessarily remain excluded from the law of blockchain.

\section{Conclusion}

Every technology and its applications are based on a dialectical relationship with social practice-and it is up to us to shape this relationship. However, it is precisely the anti-representational structure inherent in blockchain technology and the resulting robotized law and presence that constrain our scope in shaping its practical effects and implementations. This challenges us to take a closer look at the moment of transfer of the representations of law and justice into the code of blockchain.

This moment of programming the anti-representational system of blockchain can no longer be a matter of merely keeping in mind the sens commun of the consensual representation of the world, of our traditional values and principles, that take into account the physical and material dimension of our existence and its precariousness. The focus must rather lie on the more fundamental question of what a general emancipation from territory, language and body means for questions of justice, power, and other founding values, and how far we want to allow this emancipation to go. Awareness must rise to the risks involved in the transfer of certain ideas and values into programmed structures of an anti-representational, robotic (automatic self-executive) system.

Where materiality is left to the space of non-represented presence, its heteronomous force risks becoming all the more violent, especially in cases where power itself is no longer rooted either in a material sphere or in the symbolic body of an imaginary community, but operates as an acephalous structure according to criteria that are algorithmically coded — and incomprehensible to the individual. 'We must never forget that, where power and representation are concerned, the human body necessarily plays a part' (Legendre 2005, p. 155).

\section{References}

Ast, Federico. 2017. Kleros, a Protocol for a Decentralized Justice System. Medium. https://medium.com/ kleros/kleros-a-decentralized-justice-protocol-for-the-internet-38d596a6300d. Accessed 27 Nov 2020.

Ast, Federico, Clément Lesaege, and William George. 2019. Whitepaper Kleros. Kleros. https://kleros.io/ whitepaper.pdf. Accessed 27 Nov 2020.

Atzori, Marcella. 2017. Blockchain Technology and Decentralized Governance: Is the State Still Necessary? Journal of Governance and Regulation 6 (1): 45-62.

Aves, Alex. 2020. Kleros Poised for Success in the Forthcoming WFH Era. The Daily Chain. https:// thedailychain.com/kleros-poised-for-success-in-the-forthcoming-wfh-era/. Accessed 26 Aug 2020. 
Baudrillard, Jean. 1968. Le Système Des Objets. Paris: Gallimard.

Bogost, Ian. 2017. Cryptocurrency Might Be a Path to Authoritarianism. The Atlantic. https://www.theat lantic.com/technology/archive/2017/05/blockchain-of-command/528543/. Accessed 26 Nov 2020.

Ciobanu, Mirela. 2018. Blockchain — the next Stop for Storing the Digital Identity? The Paypers, https:// thepaypers.com/expert-opinion/blockchain-the-next-stop-for-storing-the-digital-identity--774086. Accessed 17 Feb 2021.

De Charentenay, Simon. 2017. Blockchain et Droit: Code is deeply Law. Blockchain France. https://block chainfrance.net/2017/09/19/blockchain-et-droit/ Accessed 26 Nov 2020.

De Filippi, Primavera, and Aaron Wright. 2015. Decentralized Blockchain Technology and the Rise of Lex Cryptographia. SSRN Electronic Journal. https://www.ssrn.com/abstract=2580664. Accessed May 15, 2021.

De Filippi, Primavera, and Aaron Wright. 2018. Blockchain and the Law: The Rule of Code. Cambridge, MA: Harvard University Press.

Fabre-Magnan, Muriel. 2018. L'institution de la liberté. Paris: PUF.

Fenton, Andrew. 2019. Blockchain Startups Think Justice Can Be Decentralized, but the Jury Is Still Out. Cointelegraph Magazine. https://cointelegraph.com/magazine/2019/12/23/blockchain-startupsthink-justice-can-be-decentralized-but-the-jury-is-still-out. Accessed 20 Apr 2021.

Filippi, De. 2018. Citizenship in the Era of Blockchain-Based Virtual Nations. In Debating Transformations of National Citizenship, ed. Rainer Bauböck, 267-278. Cham: Springer International Publishing.

Finck, Michèle. 2018. Blockchain Regulation and Governance in Europe. Cambridge: Cambridge University Press.

Fressard, Olivier. 2005. Castoriadis, Le Symbolique et l'imaginaire. In L'imaginaire Selon Castoriadis: Thèmes et Enjeux, ed. Sophie Klimis and Laurent Van Eynde, 119-150. Bruxelles: Facultés universitaires Saint-Louis.

Garapon, Antoine, and Jean Lassègue. 2018. Justice digitale. Paris: PUF.

George, William. 2018. Kleros Research Roadmap. Medium. https://medium.com/kleros/kleros-resea rch-roadmap-bfb0b77df446. Accessed 26 Apr 2021.

Goldenfein, Jake, and Andrea Leiter. 2018. Legal Engineering on the Blockchain: 'Smart Contracts' as Legal Conduct. Law and Critique 29 (2): 141-149.

Goodrich, Peter. 2006. A Theory of the Nomogram. In Law, Text, Terror, ed. Anton Schütz, Lior Barshack, and Peter Goodrich, 13-33. London: Glass House Press.

Heinemann, Torsten. 2016. Biotechnologische Grenzregime. In An Der Grenze - Die Biotechnologische Überwachung von Migration, eds. Torsten Heinemann and Martin G. Weiß. Frankfurt: Campus.

Herian, Robert. 2018. Taking Blockchain Seriously. Law and Critique 29 (2): 163-171.

Herian, Robert. 2018. The Politics of Blockchain. Law and Critique 29 (2): 129-131.

Hummler, Konrad. 2016. Blockchain—der nächste Wohlstandsschock I NZZ. Neue Zürcher Zeitung. https://www.nzz.ch/finanzen/private-finanzen/herausforderung-fuer-banken-und-den-staat-block chain-der-naechste-wohlstandsschock-ld.17609. Accessed 4 June 2020.

Legendre, Pierre. 1994. Dieu Au Miroir. Etudes Sur l'institution Des Images. Paris: Fayard.

Legendre, Pierre. 2005. Le désir politique de Dieu. Étude sur les montages de l'État du Droit. Paris: Fayard.

Legendre, Pierre. 2009. L'Autre Bible de l'Occident : Le Monument romano-canonique. Paris: Fayard.

Manski, Sarah, and Ben Manski. 2018. No Gods, No Masters, No Coders? The Future of Sovereignty in a Blockchain World. Law and Critique 29 (2): 151-162.

Metzger, James. 2019. The Current Landscape of Blockchain-Based, Crowdsourced Arbitration. Macquarie Law Journal 19: 81-101.

Musso, Pierre. 2017. La religion industrielle: Monastère, manufacture, usine: Une généalogie de l'entreprise. Paris: Fayard.

Musso, Pierre. 2021. Technique et Politique: Diabolique et Symbolique. Pistes. Revue de philosophie contemporaine. Éthique, Politique, Philosophie Des Techniques 1: 83-113.

Orgad, Liav. 2018. Cloud Communities: The Dawn of Global Citizenship? In Debating Transformations of National Citizenship, ed. Rainer Bauböck, 251-260. Cham: Springer International Publishing.

Plisson, Claire Fénéron. 2017. La blockchain, un bouleversement économique, juridique voire sociétal. I2D Information, donnees documents 54 (3): 20-22. 
Rouvroy, Antoinette. 2018. Homo Iuridicus, Est-Il Soluble Dans Les Données? In Law, Norms and Freedoms in Cyberspace / Droit, Normes et Libertés Dans Le Cybermonde, Liber Amicorum Yves Poullet, eds. Cécile de Terwangne, Elise Degrave, Séverine Dusollier, and Robert Queck. Brussels: Éditions Larcier.

Rouvroy, Antoinette, and Bernard Stiegler. 2015. Le régime de vérité numérique. De la gouvernementalité algorithmique à un nouvel État de droit. Socio. La Nouvelle Revue Des Sciences Sociales 4: $113-140$.

Schmitz, Amy, and Colin Rule. 2019. Online Dispute Resolution for Smart Contracts. Journal of Dispute Resolution 2019 (2): 103-125.

Sullivan, Clare, and Eric Burger. 2017. E-Residency and Blockchain. Computer Law \& Security Review 33 (4): 470-481.

Supiot, Alain. 2005. Homo juridicus: Essai sur la fonction anthropologique du droit. Paris: Seuil.

Supiot, Alain. 2007. Homo Juridicus: On the Anthropological Function of the Law. London: Verso.

Supiot, Alain. 2008. L'inscription Territoriale Des Lois. Esprit 11: 151-170.

Supiot, Alain. 2015. La Gouvernance par les nombres. Paris: Fayard.

Swan, Melanie. 2015. Blockchain: Blueprint for a New Economy. Sebastopol, CA: O'Reilly Media Inc.

Vigna, Paul, and Michael J. Casey. 2018. The Truth Machine: The Blockchain and the Future of Everything. New York: St. Martin's Publishing Group.

Wang, Fennie, and Primavera De Filippi. 2020. Self-Sovereign Identity in a Globalized World: Credentials-Based Identity Systems as a Driver for Economic Inclusion. Frontiers in Blockchain 2 (28): 25-46.

Weil, Simone. 1962. Selected Essays: 1934-1943. Oxford: Oxford University Press.

Winter, Eyal. 2019. On Game Theory, Decentralized Justice and Kleros. Kleros Blog. https://blog.kleros. io/eyal-winter-on-decentralized-justice/. Accessed 07 Oct 2020.

Publisher's Note Springer Nature remains neutral with regard to jurisdictional claims in published maps and institutional affiliations. 